\title{
Influence of Root Posts and Retained Coronal Dentin on Fracture Resistance and Failure Pattern of Endodontically Treated Maxillary Incisors
}

\author{
Wala Majid Amin ${ }^{\mathrm{a}, \mathrm{e}}$, Naser S Al-Huniti ${ }^{\mathrm{b}}$, Ushtar W Amin ${ }^{\mathrm{c}}$, Motasum A Abu-Awad ${ }^{\mathrm{a}}$, \\ Sheyar W Amin ${ }^{\text {, }}$, Yousef A Abousy ${ }^{\mathrm{a}}$
}

\begin{abstract}
Background: The contribution of cast metal and prefabricated fiber posts and that of retained coronal dentin to fracture resistance and failure pattern of endodontically treated maxillary incisors was evaluated.
\end{abstract}

Materials and Methods: Sixty extracted maxillary incisors were endodontically treated, prepared with full shoulder, and divided into six groups of 10 each. A $2 \mathrm{~mm}$ high axial circumferential wall of coronal dentin was left in teeth of three groups, but removed in teeth of the other groups. Post space was prepared in 40 teeth: 20 of them received cast gold posts (10 with axial ring and 10 without) and likewise the other 20 teeth received quartz fiber posts. A $2 \times 3 \mathrm{~mm}$ "well" was prepared as core foundation in the remaining 20 teeth. All teeth were restored with metal crowns. Tooth fracture strength was measured in compression at $135^{\circ}$ to its long axis until failure. Data were analyzed by analysis of variance and Tukey's tests. Mode of failure data were analyzed using Chi-square test.

Results: Root posts had no significant influence on the fracture resistance $(\mathrm{P}>0.01)$. Metal posts caused root fractures whereas failures of fiber post restored teeth were predominantly reparable.

Conclusions: Root posts did not enhance fracture resistance of endodontically treated maxillary incisors. Tooth resistance to fracture was made up by the ferrule effect afforded by the bracing of full crown against the retained coronal structures.

Manuscript accepted for publication September 26, 2013

\footnotetext{
${ }^{a}$ Department of Prosthodontics, Faculty of Dentistry, The University of Jordan, Amman, Jordan

${ }^{b}$ Faculty of Engineering, The University of Jordan, Amman, Jordan

'Intern Medical Officer, Jordan Hospital, Amman, Jordan

${ }^{\mathrm{d}}$ Faculty of Medicine, The University of Jordan, Amman, Jordan

${ }^{\mathrm{e}}$ Corresponding author: Wala Majid Amin, Department of

Prosthodontics, Faculty of Dentistry, The University of Jordan, PO Box

13455, Amman 11942, Jordan. Email: wami@ju.edu.jo
}

doi: http://dx.doi.org/10.4021/jcs204e
Keywords: Fiber post; Cast post; Root fracture; Catastrophic failure; Modulus of elasticity; Debonding; Stress concentration; Crack propagation

\section{Introduction}

Restoration of form and function of endodontically treated teeth is considered a prime objective of the operative work that follows root canal treatment. The mean of achieving this objective, however, still to the present day, is a matter of controversy. Loss of vitality of endodontically treated teeth is always accompanied by loss of moisture which presents a serious biomechanical shortcoming that makes the teeth physico-mechanically inferior to vital teeth. Destruction of tooth structure due to caries, previous restorations, and access cavity preparation renders the teeth weaker and frequently results in failure of the restorative procedures.

Many endodontically treated teeth planned for fixed prosthodontic treatment often require additional support and retention from the root by means of post restoration. The dental literature is replete of studies and reports that described various types of posts [1] but lacked a general consensus which, in other words, reflected differences of thought and belief regarding the most favorable type of post and the best restorative technique [2]. Some reports favored metallic posts due to their superior mechanical properties [2-6], whereas other reports underrated these posts on account of their high modulus of rigidity that could cause catastrophic root fractures of the teeth that they restore [7-13]. The association of metal post with the increased occurrences of root fractures had triggered the search for different types of posts that have mechanical properties comparable to those of teeth. Prefabricated fiber-reinforced composite posts have been introduced and claimed as better alternatives to metallic posts [14-16]. Fiber posts were reported as composed of fibers such as carbon, quartz, silica, zirconia, or glass, in a resin-based matrix and of anisotropic structure, whereas metal post systems have a homogenous, isotropic, structure [17-20]. It was reported that the arrangement of fibers and beads within a fiber post helps suppress stresses and loads 
exerted on the restored tooth [1]. Opponents to the use of metallic posts believed that the use of cast post-and-core systems requires extra clinical sessions and laboratory procedures that may incur added cost, subjects the root canal to infection, and increases the risk of galvanic corrosion [17, 20-22]. On the other hand, the proponents of using metallic post-and-core systems $[23,24]$ encouraged their use when more than half of the coronal tooth structure was missing in an endodontically treated tooth. It was believed that this procedure provided retention for the core which replaced the lost coronal tooth structure.

Researchers of some of the aforementioned work reported that posts strengthen the roots of endodontically treated teeth; other investigators, however, believed that fracture resistance of pulpless teeth depended mainly on the retained coronal tooth structure, and that the use of posts may compromise the resistance to fracture of pulpless teeth.

The present investigation aimed to evaluate the influence of root posts, cast metal, and prefabricated quartz fiber, and that of retained coronal structures on fracture resistance and the failure pattern of endodontically treated maxillary incisors. The hypotheses tested were, firstly, that retained coronal structure and, secondly, placement of root posts whether cast metal or prefabricated quartz fiber type do not affect the fracture resistance or failure pattern of endodontically treated maxillary incisors after quasi-static compressive loading.

\section{Materials and Methods}

A total of 60 extracted maxillary incisors were collected from the oral surgery clinics. They were thoroughly brushed clean from blood and attached soft tissues using "Asepti-Zyme" presoak cleaner (Ecolab Inc., MN, USA). The teeth were immersed in 5\% sodium hypochlorite disinfectant for 24 hours, and then stored in distilled water. Teeth were inspected and accepted for uniformity of root shape. They were cross-sectioned at an $18 \mathrm{~mm}$ distance from the root tip using a high speed rotary diamond separating disc (SS White Burs, Inc., Lakewood, NJ, USA) so that the flat and smooth sectioned root face was normal to the long axis of the root.

Root canal filling of all teeth was carried out by one operator using rotary Protaper ${ }^{\circledR}$ system (Quality Endodontic Distributors Ltd, Peterborough, UK) and 2.5\% sodium hypochlorite solution for irrigation. In order to standardize the shape of the root canals of all employed teeth, all canals were shaped up to F3 size file and were, consequently, obturated using system-based Gutta percha points and ZX sealer (DENTSPLY Ltd, Addlestone, Surrey, UK). The external surfaces of the roots were mechanically scored using a diamond separating disc (SS White Burs, Inc., Lakewood, NJ, USA); the roughened root surface was indented to help fix the root and stabilize it within its mount during testing. The roots were coated with a thin film (approximately $0.5 \mathrm{~mm}$ thick) of silicon-based impression material (Speedex, Coltene, Switzerland). This artificial layer was used to simulate the periodontal ligament during fracture test. The teeth were, then, mounted into copper rings filled with self-polymerized acrylic resin (Palapress, Heraeus Kulzer, Newbury, Berkshire, UK). A dental surveyor (Ferraro Eng., Hereford, AZ, USA) was used to ensure that the long axes of the mounted teeth were perpendicular to the horizontal plane. A distance of $5 \mathrm{~mm}$ of the tooth height in the coronal direction was left unmounted but emerged out of the acrylic resin surface in the copper ring.

All 60 teeth were prepared with full shoulder, and divided into six groups of 10 each. Of the unmounted $5 \mathrm{~mm}$ length, $2 \mathrm{~mm}$ high ring-shaped axial wall covering the circumference of the tooth incisal to the finish line was prepared in teeth of three groups (30 teeth), but was removed in teeth of the other groups. The remaining $3 \mathrm{~mm}$ of unmounted distance represented the height of the simulated bone level. Post space was prepared in 40 roots to the depth of $13 \mathrm{~mm}$ and standard dimensions using the same size drills (provided in the system kit of D.T. Light Posts Illusion, RTD. Manufacturing Co. Ltd, Saint Egreve, France). The thickness of the dentin between the root perimeter and the prepared post space was measured for all roots using a computerized digital caliper (CDC) and custom-made software [25], and the average dentin thicknesses for each group were presented in Table 1 . Twenty of the 40 teeth in which post spaces were prepared (10 teeth with axial ring of coronal dentin and the other 10 without) received cast gold posts (Degussa Ney Dental Inc., Yucaipa, CA, USA). Likewise, the other 20 teeth, 10 with axial ring of coronal dentin and 10 without, received quartz fiber posts (D.T. Light Posts Illusion, RTD. Manufacturing Co. Ltd, Saint Egreve, France).

The remaining 20 teeth of the sample (10 teeth with axial ring of coronal dentin and 10 without) served as a control group. A $2 \times 3 \mathrm{~mm}$ "well" was prepared at the coronal aspect of the root canal orifice in each of the control group teeth and functioned as core foundation. Composite core was built in each tooth specimen of the entire sample and then prepared for a full metal crown. The prepared core was lubricated using petroleum jelly (NRS Global Partners, Kuala Lumpur, Malaysia) and on which a blue inlay wax (Richter \& Hoffmann Harvard Dental GmbH, Berlin, Germany) pattern for a full metal crown restoration was formed using the appropriate size readymade polycarbonate resin central incisor crown form (SDI, Svenska Dental Instrument AB, Soha, Sweden). A transverse groove, $1 \mathrm{~mm}$ deep, was scored across the palatal surface $3 \mathrm{~mm}$ away from the incisal edge of the wax pattern. The scored groove confined to the chisel blade of the loading device simulating the incisal edge of a lower central incisor. The wax patterns were invested in a high expansion phosphate-bonded investment material (GC Fujivest II; GC America Inc., Alsip, IL, USA) and cast using a high-palladium alloy (Ultima Lite; Dentsply Ceram- 
Table 1. Thickness of Root Dentin (mm) After Preparing Post Space

\begin{tabular}{lllll}
$\begin{array}{l}\text { Prepared tooth specimens for } \\
\text { restoration with the following post } \\
\text { systems }\end{array}$ & \multicolumn{3}{l}{ Thickness of root dentin (mm) after preparing post space } \\
\cline { 2 - 5 } & $\begin{array}{l}\text { Mean } \\
(\mathbf{n = 2 0})\end{array}$ & St dev. & $\begin{array}{l}\text { Lowest dentin } \\
\text { thickness }\end{array}$ & $\begin{array}{l}\text { Highest dentin } \\
\text { thickness }\end{array}$ \\
\hline Metal posts & 1.26 & $( \pm) 0.22$ & 0.98 & 1.51 \\
Fiber posts & 1.23 & $( \pm) 0.26$ & 0.69 & 1.07 \\
\hline
\end{tabular}

co, Burlington, NJ, USA). The cast crowns were cemented (Nexus 2; Kerr Dental).

A custom designed and manufactured holding grip was used to insure that the tooth specimen was housed firmly at the point of load application by the universal testing machine (Fig. 1) (WP 310 Hydraulic Universal Tester equipped with a PC-aided data-recording system, G.U.N.T. Geratebau $\mathrm{GmbH}$, Barsbuttel, Germany), which was employed to apply a quasi-static compressive load to tooth specimens with a crosshead speed of $0.5 \mathrm{~cm} / \mathrm{min}[11,26]$ at an angle of $135^{\circ}$ to the long axis of teeth until failure occurred. The inclined compressive force was applied to the notch on the palatal surface of the crowns. Force data applied over time were recorded using the universal testing machine's computer software. The failure of the specimen was determined when the force-versus-time graph showed an abrupt change in load, indicating a sudden decrease in the specimen's resistance to compressive loading.

The collected data sets were treated statistically using analysis of variance (ANOVA) to compare means of fracture resistance among the various test groups. The two-way ANOVA helped evaluate the influence of root posts on specimens' fracture resistance and that of the presence of retained coronal dentin as well as the interaction between these two variables. Multiple comparisons among the investigated test groups were carried out using Tukey's test whereby the groups that were statistically different from others were identified. The metal crowns of the test specimens were split opened, after they had been tested for fracture resistance, and all tested teeth were visually and radiographically examined for evaluation of the pattern of failure and detection of the direction of cracks when occurred. Fractures above the embedded resin, namely, the simulated bone level were considered reparable and those below the resin level were considered irreparable. The influence of post type and that of residual coronal dentin on the mode of failure was statistically analyzed using Chi-square test. The statistical analyses of the various data sets were conducted at $99 \%$ confidence level.

\section{Results}

The mean force to fracture of the test specimens is presented in Table 2 and displayed in Figure 2. The fracture resistance of teeth to quasi-static compressive loading varied substantially among the different test groups. Pairwise comparisons using two-way ANOVA indicated that a positive contribution to tooth fracture resistance was demonstrated by the presence of the $2 \mathrm{~mm}$ high circumferential ring of retained coronal dentin. The revealed significant influence ("F" $=48.260$ and $\mathrm{P}<0.01$ ) of the residual coronal dentin on tooth resistance to fracture was clearly demonstrated by the control group tooth specimens which did not receive a root post restoration. That was further confirmed by teeth of the other groups, regardless the type of root post employed in their restoration. Absence of the coronal residual dentin incurred a substantial loss, approximately $80 \%$, in the magnitude of tooth resistance to fracture. Tukey's HSD test for post hoc multiple comparisons (Table 3) revealed that root posts, whether cast metal or prefabricated fiber type, did not

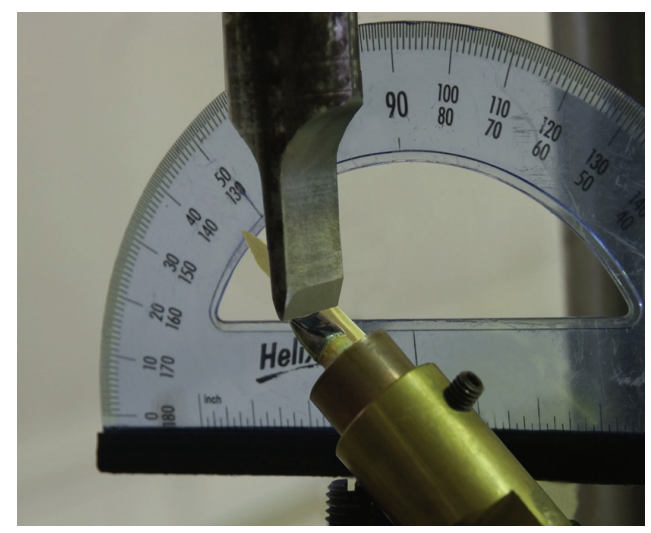

Figure 1. A mounted specimen positioned at $135^{\circ}$ angle in a custom made holding grip used in the universal testing machine (MTS 858; MTS Systems Corp., Eden Prairie, MN, USA) employed for fracture resistance testing (From Amin et. al. JMMS; vol.(9):343-352, 2013). 
Table 2. Force to Failure of Endodontically Treated Root-Post Restored Maxillary Incisors

Force (N) to failure (mean \pm St dev.) $(n=10)$

Crown ferrule orientation

\begin{tabular}{llll} 
& Metal & Fiber & Control \\
\cline { 2 - 4 } Ring ferrule & $374( \pm 163)^{\mathrm{A}}$ & $310( \pm 49)^{\mathrm{A}}$ & $257.5( \pm 96)^{\mathrm{A}}$ \\
No ferrule & $76( \pm 60)^{\mathrm{B}}$ & $80( \pm 43)^{\mathrm{B}}$ & $54( \pm 57)^{\mathrm{B}}$ \\
\hline
\end{tabular}

Note: Different alphabets denote significant differences at $99 \%$ confidence level.

play any significant role in enhancing tooth fracture resistance ("F" $=5.509$ and $\mathrm{P}>0.01$ ). Comparisons made among groups of cast post restored, fiber post restored, and control group teeth that did not have coronal dentin ring, showed no significant difference in the magnitude of resistance to fracture ("F" = 3.184 and $\mathrm{P}>0.01$ ).

The prevalence of failure pattern of test specimens is presented in Figure 3. Analyses of failures revealed a predominance of irreparable failures demonstrated by the metal post restored teeth (Fig. 3). About $80 \%$ of these specimens (16 teeth out of 20) exhibited a significantly high incidence of middle third root fractures (Chi-square 10.7 and $\mathrm{P}=$ 0.006 ) (Fig. 4A). The remaining $20 \%$ of the metal post restored teeth (4 out of 20 tooth specimens) displayed core fragmentations (Fig. 4B) which were considered restorable cases. Reparable failure mode demonstrated by the fiber post restored teeth was significantly higher (Chi-square 30.1 and $\mathrm{P}=0.001$ ) (Fig. 3) compared with the metal post restored teeth. Fourteen out of 20 specimens of this group showed reparable failure pattern of different types, of which $20 \%$ (4 out of 20 teeth) showed core debonding without post fracture (Fig. 4C); 10\% (2 out of 20 teeth) exhibited root post adhesive failure (Fig. 4D), and 40\% (8 out of 20 teeth) demonstrated crown-core-post complex fracture with cracks extending above the assumed bone level (Fig. 4E). Irreparable failure mode was observed in about $30 \%$ (6 out of 20 teeth) of this group, in which tooth specimens failed by crowncore-post complex fracture with cracks that extended below

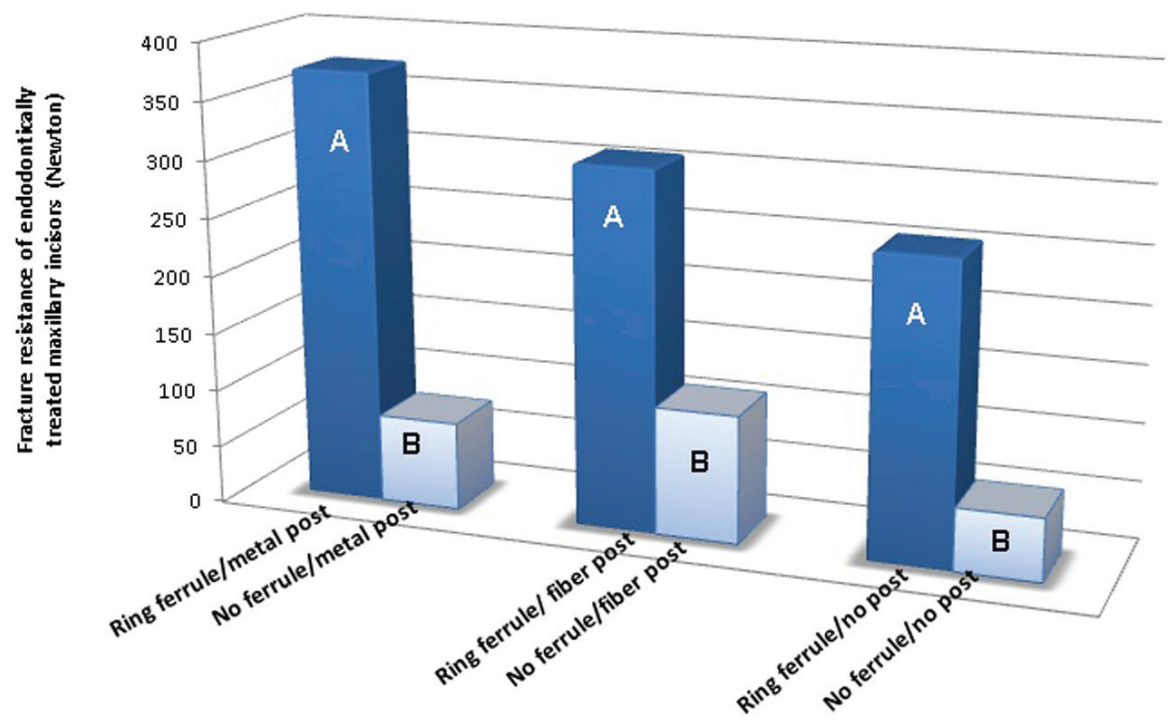

Figure 2. Significance of root posts to fracture resistance of restored endodontically treated maxillary incisors. Different alphabets (inserts) denote statistically significant difference at $99 \%$ confidence level. 
Table 3. Group Mean Differences. When the Obtained Tukey's "T" Value of 176 was Smaller Than the Difference Between Two Means, the Means Would Be Significantly Different

\begin{tabular}{|c|c|c|c|c|c|c|}
\hline \multirow{2}{*}{ Post system } & \multirow{2}{*}{$\begin{array}{l}\text { Means } \\
(n=10)(N)\end{array}$} & \multicolumn{5}{|c|}{ Comparison mean differences } \\
\hline & & M2 & M3 & M4 & M5 & M6 \\
\hline $\begin{array}{l}\text { Ring ferrule } \\
\text { metal post }\end{array}$ & $\mathrm{M} 1=374$ & $\mathrm{M} 1-\mathrm{M} 2=298^{* *}$ & $\mathrm{M} 1-\mathrm{M} 3=64^{\mathrm{NS}}$ & M1-M4 $=294^{* *}$ & $\mathrm{M} 1-\mathrm{M} 5=116.5^{\mathrm{NS}}$ & $\mathrm{M} 1-\mathrm{M} 6=320^{* *}$ \\
\hline $\begin{array}{l}\text { No ferrule } \\
\text { metal post }\end{array}$ & $\mathrm{M} 2=76$ & & $\mathrm{M} 3-\mathrm{M} 2=234^{* *}$ & $\mathrm{M} 4-\mathrm{M} 2=4^{\mathrm{NS}}$ & $\mathrm{M} 5-\mathrm{M} 2=181.5^{* *}$ & $\mathrm{M} 2-\mathrm{M} 6=22^{\mathrm{NS}}$ \\
\hline $\begin{array}{l}\text { Ring ferrule } \\
\text { fiber post }\end{array}$ & $\mathrm{M} 3=310$ & & & $\mathrm{M} 3-\mathrm{M} 4=230^{* *}$ & $\mathrm{M} 3-\mathrm{M} 5=52.5^{\mathrm{NS}}$ & $\mathrm{M} 3-\mathrm{M} 6=256^{* *}$ \\
\hline $\begin{array}{l}\text { No ferrule } \\
\text { fiber post }\end{array}$ & $\mathrm{M} 4=80$ & & & & M5-M4 $=177.5^{* *}$ & $\mathrm{M} 4-\mathrm{M} 6=26^{\mathrm{NS}}$ \\
\hline $\begin{array}{l}\text { Ring ferrule } \\
\text { no post }\end{array}$ & $\mathrm{M} 5=257.5$ & & & & & $\mathrm{M} 5-\mathrm{M} 6=203.5^{* *}$ \\
\hline $\begin{array}{l}\text { No ferrule no } \\
\text { post }\end{array}$ & M6 $=54$ & & & & & \\
\hline
\end{tabular}

** denotes significant difference $\mathrm{P}<0.01$. NS indicates not significant difference.

the assumed bone level (Fig. 4F).

\section{Discussion}

The present investigation shed light on the role played by the retained coronal residual structures and that by placement of root posts, cast gold, and prefabricated quartz fiber types, on fracture resistance of endodontically treated teeth after being subjected to quasi-static compressive loading. The hypothesis that a retained $2 \mathrm{~mm}$ high axial circumferential ring of coronal residual dentin does not affect the fracture resistance of endodontically treated teeth has been rejected. The hypothesis that placing cast gold or prefabricated quartz fiber root posts does not affect the fracture resistance or failure pattern of endodontically treated maxillary incisors has been accepted.

The results showed that preserving a $2 \mathrm{~mm}$ high circumferential ring of retained coronal dentin significantly enhanced the fracture resistance of restored endodontically treated teeth $(\mathrm{P}=0.001)$. The retained coronal dentin helped provide the resistance form of crown preparations which was made up by the bracing effect afforded by the crown when it is placed over tooth structure or core foundation. This bracing effect is known as the "ferrule effect $[27,28]$. Our findings indicated that the fracture resistance of restored end- odontically treated teeth was dependent on the presence of retained residual coronal dentin. These results confirmed the findings of some past reports $[29,30]$, but contrasted those of another study [31] which reported that ferrules do not enhance fracture resistance of post-endodontic restoration.

The use of root posts in restoring endodontically treated teeth remained a controversial issue. The results of the present investigation indicated that placement of a root post, cast metal or prefabricated fiber post, did not significantly improve the resistance to fracture of maxillary incisors restored with full metal crowns whether a ferrule was present or not. This was in agreement with the findings of previously published reports [32-36] which showed that insertion of a post does not add any beneficial effect to teeth, even in the anterior region where higher tension stress due to more horizontal forces develops during function. Post placement has also been shown not to improve marginal adaptation, retention, and fracture resistance of adhesive composite restorations on endodontically treated premolars [37-39]. Our findings, however, contrasted some past reported findings [32, 40, 41] which pointed out that post placement was not significant in teeth with substantial remaining coronal structure but could be efficacious to reduce failures of post endodontic restorations for teeth with no residual coronal walls. Some studies revealed that teeth restored with fiber posts were shown to exhibit more fracture resistance compared to teeth restored 


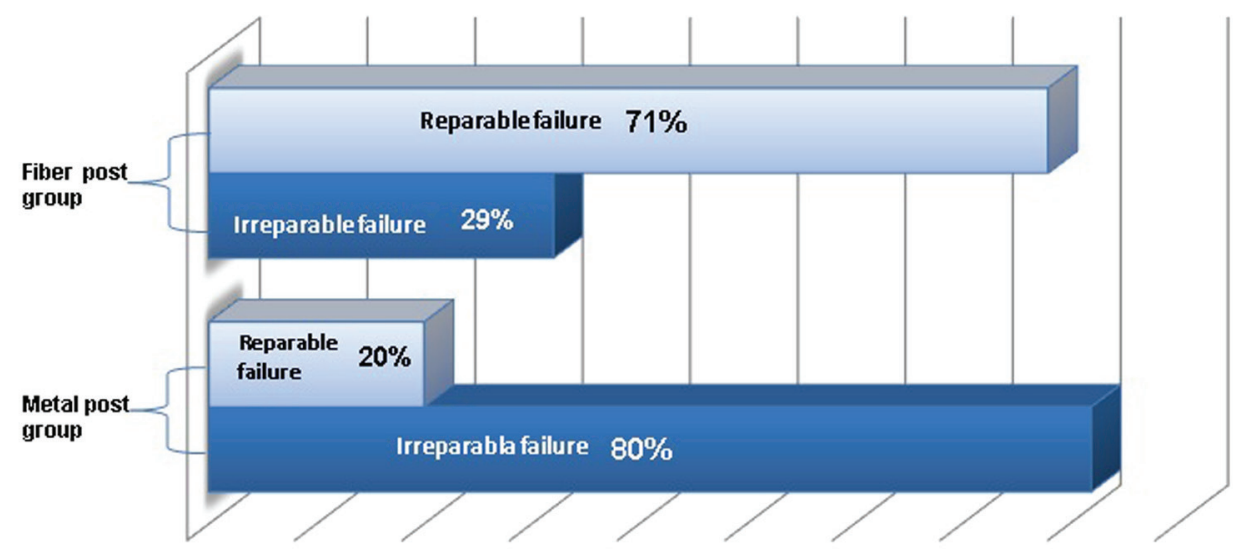

Figure 3. Reparable/irreparable failure mode fraction of the endodontically treated maxillary incisors restored with metal and fiber root post systems.

without posts. Other studies reported that teeth restored with prefabricated stainless steel posts showed higher fracture resistance than those restored with carbon or ceramic posts $[16,31]$, and also higher than that of teeth restored with cast metal or glass fiber posts [17, 32, 34]. Our results, however, threw doubts on these findings and showed that in the absence of retained coronal structure, placement of root posts, both cast metal and prefabricated fiber types, incurred not more than an insignificant $28 \%$ increase in tooth fracture resistance. Our results revealed that fracture resistance of teeth restored by either type of root posts was not significantly different from that of teeth which did not receive root post restoration.

In addition to tooth fracture resistance property, success of a restoration has to be regarded as the chance of re-intervention and preservation of the restored tooth when failure has happened [39]. It may be more favorable that failure occurs at a lower load but in a way that it would not inflict structural damage to tooth integrity but maintains the tooth reparable. This entails that the ideal post system selected for restoring an endodontically treated tooth should exhibit fracture resistance more than the average physiologic masticatory force, but should not be too high to yield a catastrophic root fracture. Fracture resistance is of greater importance than retention because post can be recemented if dislodged from the tooth. However, if the root fractures, the tooth is invariably lost [41]. It is essential, therefore, that a post should not be evaluated on its size or rigidity but its ability to respect the root structure. In the present investigation, the level of embedding of the tooth specimen in the autopolymerized resin was $3 \mathrm{~mm}$ below the cemento-enamel junction, which simulated the level of the alveolar bone. The mode of failure was considered reparable or irreparable depending on whether the fracture of the tooth specimen was above or below the embedding resin, respectively. Fractures above the resin level were considered reparable as retreatment could be initiated due to accessibility and the adequate amount of remaining tooth structure present to provide restorative treatment. The fracture of the specimen below the embedded resin was considered irreparable as treatment would be difficult [42]. In this study, $80 \%$ of the specimens restored with cemented cast metal posts failed because of root fracture, and very few failed because of core fragmentation. Despite that these failures occurred at a higher load compared with that at which the fiber post restored counterparts failed, the root fracture displayed by these specimens was considered a catastrophic event which only leads to an inevitable loss of these teeth. On the other hand, more than $70 \%$ of the fiber post restored teeth exhibited reparable failures showing core debonding, post adhesive failure, or crown-core-post complex fracture above simulated bone level. The results of this study were consistent with those of previous studies that reported a root fracture mode of failure was always associated with metal post restored teeth $[3,12,18,26,28,31,36$, 40-46] whereas teeth restored with prefabricated fiber post systems predominantly failed by post or core fracture without damaging the root. This finding pointed to the correlation that exists between post material and fracture of roots. It has been postulated that ideally, the post material should have the same modulus of elasticity as the root dentin in order to distribute the applied force evenly along the length of the post and the root. When a system with components of different rigidity is loaded, the more rigid component is capable of resisting forces without distortion. The less rigid component fails and relieves stresses [20]. In the case of a metal post restored endodontically treated tooth, the released stresses initiate cracks that would propagate within the root and result in root fracture. In the present context, the modulus of elasticity of dentin is approximately 18-22 GPa [47], and according to the manufacturers of the materials employed in this 


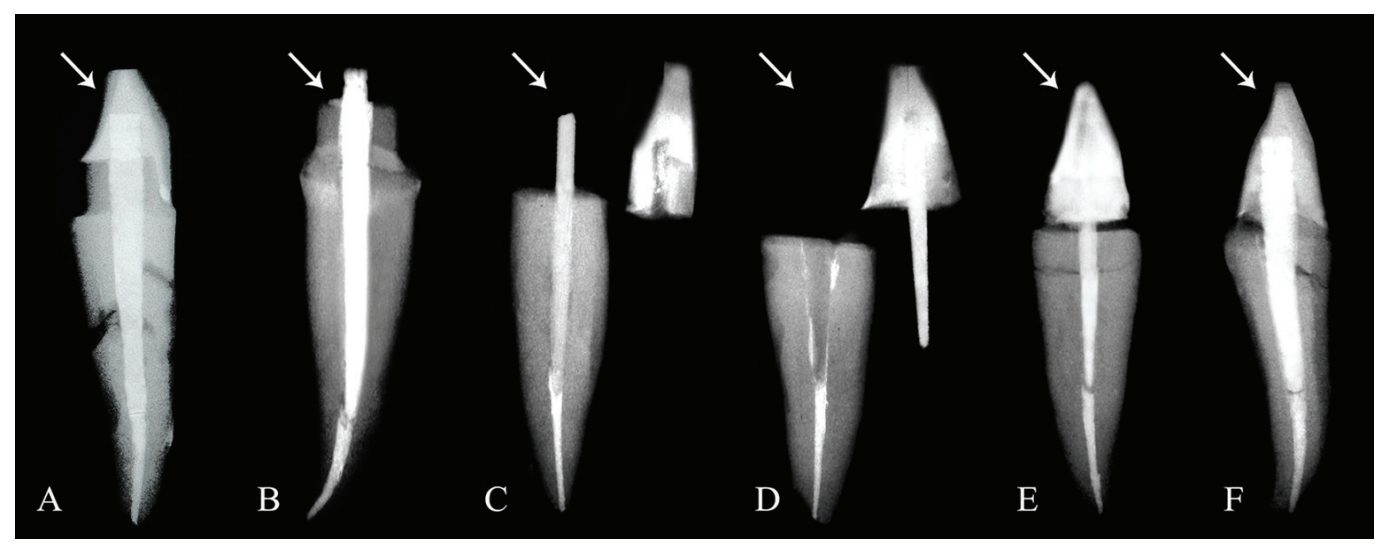

Figure 4. Radiographs of a sample of endodontically treated teeth demonstrating various modes of failure after being subjected to fracture resistance test. (A) a metal post restored specimen with a full-ring coronal dentin ferrule showing an irreparable middle third root fracture; (B) a metal post restored specimen showing fragmented core without post fracture; (C) a fiber post restored specimen showing core debonding without post fracture; (D) a fiber post restored tooth displaying root/post adhesive failure; $(E)$ a fiber post restored tooth demonstrating a crown-core-post complex fracture with cracks extending above the assumed bone level; (F) a fiber post restored tooth exhibiting an irreparable crown-core-post complex fracture with a palato-labial oblique crack running below the simulated bone level.

investigation, the fiber posts' modulus is about 23-29 GPa. This close similarity in elasticity would allow post flexion mimicking that of the tooth. This makes it very likely that when the tooth specimen was loaded, the fiber post had absorbed and distributed the stresses and thus, transmitted only reduced stresses to the root. The longitudinal arrangement of fibers in the post and its elastic modulus that is nearly equal to that of the dentin would help redistribute the stresses into the tooth in a fashion that would increase the likelihood of failure of the post-core/root interface instead of root fracture. In contrast, the modulus of rigidity of the cast metal post is approximately $91 \mathrm{GPa}$ [48], that is more than four times that of dentin. This makes it stiff, unyielding and therefore unable to absorb stresses but concentrates them, resulting in an irreparable root fracture.

The results of the present study showed that even though the magnitude of fracture resistance of the fiber post was relatively inferior to that of the metal post, the former performed superiorly when fracture mode was taken as a parameter.

\section{Limitations of the study}

The outcomes of this study provided an insight on the implications of the findings onto the clinical situation. However, clinical applications based on the principles stemmed from the outcomes of this study must not be practiced right away. Further research work is required on larger samples comprising both anterior and posterior teeth and using wider range of chemically different root post systems. Specimens should preferably be tested in dynamic conditions mimicking the intraoral environment. The role that can be played by retained residual coronal structures/walls beyond the $2 \mathrm{~mm}$ high ferrule and their location relative to tooth circumference should be adequately evaluated.

\section{Conclusion}

Within the limits of this in vitro study, it was concluded that placement of root posts seemed not to be necessary to improve the fracture resistance of endodontically treated maxillary incisors. The fracture resistance of the teeth is mainly made up by the bracing effect of crowns against retained circumferential ring of coronal dentin.

\section{Acknowledgement}

The authors express their sincere gratitude to Mr. Mazin Alborini of the dental lab at the Jordan University Hospital for his help in fabricating the metal crowns of the test specimens. Special thanks go to Mrs. Sana'a Karazoun of the "Materials' lab." at the faculty of Engineering and Technology for her invaluable help and assistance in conducting the quasi-static compressive tests.

\section{Disclosure Statement}

The authors have no conflict of interest.

\section{References}

1. Fernandes AS, Shetty S, Coutinho I. Factors determining post selection: a literature review. J Prosthet Dent. 2003;90(6):556-562. 
2. Martinez-Insua A, da Silva L, Rilo B, Santana U. Comparison of the fracture resistances of pulpless teeth restored with a cast post and core or carbon-fiber post with a composite core. J Prosthet Dent. 1998;80(5):527-532.

3. Asmussen E, Peutzfeldt A, Sahafi A. Finite element analysis of stresses in endodontically treated, dowelrestored teeth. J Prosthet Dent. 2005;94(4):321-329.

4. Toksavul S, Zor M, Toman M, Gungor MA, Nergiz I, Artunc C. Analysis of dentinal stress distribution of maxillary central incisors subjected to various post-andcore applications. Oper Dent. 2006;31(1):89-96.

5. Akkayan B, Gulmez T. Resistance to fracture of endodontically treated teeth restored with different post systems. J Prosthet Dent. 2002;87(4):431-437.

6. Fokkinga WA, Kreulen CM, Vallittu PK, Creugers NH. A structured analysis of in vitro failure loads and failure modes of fiber, metal, and ceramic post-and-core systems. Int J Prosthodont. 2004;17(4):476-482.

7. Isidor F, Odman P, Brondum K. Intermittent loading of teeth restored using prefabricated carbon fiber posts. Int J Prosthodont. 1996;9(2):131-136.

8. Ferrari M, Vichi A, Mannocci F, Mason PN. Retrospective study of the clinical performance of fiber posts. Am J Dent. 2000;13(Spec No):9B-13B.

9. Mannocci F, Ferrari M, Watson TF. Intermittent loading of teeth restored using quartz fiber, carbon-quartz fiber, and zirconium dioxide ceramic root canal posts. J Adhes Dent. 1999;1(2):153-158.

10. Heydecke G, Butz F, Hussein A, Strub JR. Fracture strength after dynamic loading of endodontically treated teeth restored with different post-and-core systems. J Prosthet Dent. 2002;87(4):438-445.

11. Sidoli GE, King PA, Setchell DJ. An in vitro evaluation of a carbon fiber-based post and core system. J Prosthet Dent. 1997;78(1):5-9.

12. Sirimai S, Riis DN, Morgano SM. An in vitro study of the fracture resistance and the incidence ofvertical root fracture of pulpless teeth restored with six post-andcoresystems. J Prosthet Dent. 1999;81(3):262-269.

13. Newman MP, Yaman P, Dennison J, Rafter M, Billy E. Fracture resistance of endodontically treated teeth restored with composite posts. J Prosthet Dent. 2003;89(4):360-367.

14. Christensen GJ. Post concepts are changing. J Am Dent Assoc. 2004;135(9):1308-1310.

15. Qualtrough AJ, Mannocci F. Tooth-colored post systems: a review. Oper Dent. 2003;28(1):86-91.

16. De Santis R, Prisco D, Apicella A, Ambrosio L, Rengo $\mathrm{S}$, Nicolais L. Carbon fiber post adhesion to resin luting cement in the restoration of endodontically treated teeth. J Mater Sci Mater Med. 2000;11(4):201-206.

17. Mitsui FH, Marchi GM, Pimenta LA, Ferraresi PM. In vitro study of fracture resistance of bovine roots using different intraradicular post systems. Quintessence Int.
2004;35(8):612-616.

18. Bolhuis P, de Gee A, Feilzer A. Influence of fatigue loading on four post-and-core systems in maxillary premolars. Quintessence Int. 2004;35(8):657-667.

19. Stockton LW, Williams PT. Retention and shear bond strength of two post systems. Oper Dent. 1999;24(4):210216.

20. King PA, Setchell DJ, Rees JS. Clinical evaluation of a carbon fibre reinforced carbon endodontic post. J Oral Rehabil. 2003;30(8):785-789.

21. Al-harbi F, Nathanson D. In vitro assessment of retention of four esthetic dowels to resin core foundation and teeth. J Prosthet Dent. 2003;90(6):547-555.

22. Lassila LV, Tanner J, Le Bell AM, Narva K, Vallittu PK. Flexural properties of fiber reinforced root canal posts. Dent Mater. 2004;20(1):29-36.

23. Christensen GJ. Posts and cores: state of the art. J Am Dent Assoc. 1998;129(1):96-97.

24. Federick DR. An application of the dowel and composite resin core technique. J Prosthet Dent. 1974;32(4):420424.

25. Amin WM, Taha ST, Al-Tarawneh SK, Saleh MW, Ghzawi A. The relationships of the maxillary central incisors and canines to the incisive papilla in Jordanians. J Contemp Dent Pract. 2008;9(5):42-51.

26. Padmanabhan P. A comparative evaluation of the fracture resistance of three different pre-fabricated posts in endodontically treated teeth: An in vitro study. J Conserv Dent. 2010;13(3):124-128.

27. Shillingburg Jr. HT, Kessler JC. Restoration of endodontically treated tooth, 1st ed. Illinois, Quintessence Publishing, 1982;14-20.

28. Ng CC, Dumbrigue HB, Al-Bayat MI, Griggs JA, Wakefield CW. Influence of remaining coronal tooth structure location on the fracture resistance of restored endodontically treated anterior teeth. J Prosthet Dent. 2006;95(4):290-296.

29. da Silva NR, Raposo LH, Versluis A, Fernandes-Neto AJ, Soares CJ. The effect of post, core, crown type, and ferrule presence on the biomechanical behavior of endodontically treated bovine anterior teeth. J Prosthet Dent. 2010;104(5):306-317.

30. Akkayan B. An in vitro study evaluating the effect of ferrule length on fracture resistance of endodontically treated teeth restored with fiber-reinforced and zirconia dowel systems. J Prosthet Dent. 2004;92(2):155-162.

31. Mangold JT, Kern M. Influence of glass-fiber posts on the fracture resistance and failure pattern of endodontically treated premolars with varying substance loss: an in vitro study. J Prosthet Dent. 2011;105(6):387-393.

32. Zicari F, Van Meerbeek B, Scotti R, Naert I. Effect of ferrule and post placement on fracture resistance of endodontically treated teeth after fatigue loading. J Dent. 2013;41(3):207-215. 
33. Cagidiaco MC, Garcia-Godoy F, Vichi A, Grandini S, Goracci C, Ferrari M. Placement of fiber prefabricated or custom made posts affects the 3-year survival of endodontically treated premolars. Am J Dent. 2008;21(3):179-184.

34. Salameh Z, Sorrentino R, Ounsi HF, Goracci C, Tashkandi E, Tay FR, Ferrari M. Effect of different all-ceramic crown system on fracture resistance and failure pattern of endodontically treated maxillary premolars restored with and without glass fiber posts. J Endod. 2007;33(7):848-851.

35. Sorrentino R, Monticelli F, Goracci C, Zarone F, Tay FR, Garcia-Godoy F, Ferrari M. Effect of post-retained composite restorations and amount of coronal residual structure on the fracture resistance of endodonticallytreated teeth. Am J Dent. 2007;20(4):269-274.

36. Heydecke G, Butz F, Strub JR. Fracture strength and survival rate of endodontically treated maxillary incisors with approximal cavities after restoration with different post and core systems: an in-vitro study. J Dent. 2001;29(6):427-433.

37. Krejci I, Duc O, Dietschi D, de Campos E. Marginal adaptation, retention and fracture resistance of adhesive composite restorations on devital teeth with and without posts. Oper Dent. 2003;28(2):127-135.

38. Ferrari M, Cagidiaco MC, Grandini S, De Sanctis M, Goracci C. Post placement affects survival of endodontically treated premolars. J Dent Res. 2007;86(8):729734.

39. Fokkinga WA, Kreulen CM, Bronkhorst EM, Creugers $\mathrm{NH}$. Up to 17-year controlled clinical study on post-andcores and covering crowns. J Dent. 2007;35(10):778786.
40. Bitter K, Noetzel J, Stamm O, Vaudt J, Meyer-Lueckel H, Neumann K, Kielbassa AM. Randomized clinical trial comparing the effects of post placement on failure rate of postendodontic restorations: preliminary results of a mean period of 32 months. J Endod. 2009;35(11):14771482.

41. Maccari PC, Conceicao EN, Nunes MF. Fracture resistance of endodontically treated teeth restored with three different prefabricated esthetic posts. J Esthet Restor Dent. 2003;15(1):25-30; discussion 31.

42. Raygot CG, Chai J, Jameson DL. Fracture resistance and primary failure mode of endodontically treated teeth restored with a carbon fiber-reinforced resin post system in vitro. Int J Prosthodont. 2001;14(2):141-145.

43. Wadhwani KK, Shrivastava S, Nigam P. Comparative evaluation of fracture resistance of various post systems: An in vitro study. J Conserv Dent. 2003;6:56-61.

44. Fraga RC, Chaves BT, Mello GS, Siqueira JF, Jr. Fracture resistance of endodontically treated roots after restoration. J Oral Rehabil. 1998;25(11):809-813.

45. Torbjorner A, Fransson B. Biomechanical aspects of prosthetic treatment of structurally compromised teeth. Int J Prosthodont. 2004;17(2):135-141.

46. Dean JP, Jeansonne BG, Sarkar N. In vitro evaluation of a carbon fiber post. J Endod. 1998;24(12):807-810.

47. Makade CS, Meshram GK, Warhadpande M, Patil PG. A comparative evaluation of fracture resistance of endodontically treated teeth restored with different post core systems - an in-vitro study. J Adv Prosthodont. 2011;3(2):90-95.

48. Greener E.H, Harcourt J.K, Lautenschlager E.R. Mechanical properties. In: Materials Science in Dentistry 1st ed. Baltimore, William \& Wilkins, 1972;44-64. 